\title{
Gaining knowledge via other minds: Children's flexible trust in others as sources of information
}

\author{
Elizabeth J. Robinson*, Stephen A. Butterfill and Erika Nurmsoo \\ Warwick University, Coventry, UK
}

\begin{abstract}
In five experiments, we examined 3- to 6-year-olds' understanding that they could gain knowledge indirectly from someone who had seen something they had not. Consistent with previous research, children judged that an informant, who had seen inside a box, knew its contents. Similarly, when an informant marked a picture to indicate her suggestion as to the content of the box, 3- to 4-year-olds trusted this more frequently when the informant had seen inside the box than when she had not. Going beyond previous research, 3- to 4-year-olds were also sensitive to informants' relevant experience when they had to look over a barrier to see the marked picture, or ask for the barrier to be raised. Yet when children had to elicit the informant's suggestion, rather than just consult a suggestion already present, even 4- to 5-year-olds were no more likely to do so when the informant had seen the box's content than when she had not, and no more likely to trust the well-informed suggestion than the uninformed one. We conclude that young children who can ask questions may not yet fully understand the process by which they can gain accurate information from someone who has the experience they lack.
\end{abstract}

If I want to find out the content of a box, the most reliable and direct way is to look inside. But if that is not possible, then I might be able to find out indirectly from someone else whom I know to have seen inside. That person might happen to announce the content in y hearing, or I could consult a record she has made of the content, or I could ask her to tell me the content. In each of these cases, I can be nearly as confident that I know what is in the box as I would be had I seen inside myself, unless I have reason to doubt the reliability of the person. This confidence depends on my recognizing that the other person has had a particular experience, seeing inside the box, that yields the knowledge I seek. Adults often learn from others in circumstances such as this. For example, just as you are about to eat a biscuit, I warn you that the dog licked it while you were on the telephone. You see me checking the outside temperature and ask me how cold it is. In the experiments reported here, we examine the extent of children's understanding that

Erika Nurmsoo is now at University of Kent, UK.

*Correspondence should be addressed to Elizabeth J. Robinson, Department of Psychology, Warwick University, Coventry, CV4 7 AL, UK (e-mail: e.j.robinson@warwick.ac.uk). 
they can gain knowledge indirectly from others who have had a particular experience they lack.

We already know something about children's understanding about gaining knowledge from others who have had relevant experience. In previous research, when 3to 4-year-olds were offered information unsolicited, they were more likely to believe an informant when she was well informed than when she was ignorant. For example, children believed what the informant told them about the colour of a hidden toy when she had looked at it, but disregarded what she told them when she had only felt it or had no access at all. Conversely, they believed what the informant said about the hidden toy's softness when she had felt it, but disregarded that when she had only seen it. That is, children saw the implications of the informant's experience for the likely truth of what she subsequently said, and showed appropriate flexibility in their trust (Nurmsoo \& Robinson, 2009a; 2009b; Robinson, Champion, \& Mitchell, 1999; Robinson \& Whitcombe, 2003; Whitcombe \& Robinson, 2000). This flexibility stands in marked contrast to the trust that children place in speakers by virtue of their past history of accuracy (e.g., Koenig \& Harris, 2005; Nurmsoo \& Robinson, 2009a) or other characteristics such as age and expertise (e.g., Jaswal \& Neely, 2007). In these latter studies, children trusted informants because they had demonstrated knowledge within a particular domain, or because they had characteristics predictive of such knowledge, rather than by virtue of the child witnessing the informant gaining the specific experience the child lacks.

In the tasks listed above (Nurmsoo \& Robinson, 2009b; Robinson et al., 1999; Robinson \& Whitcombe, 2003; Whitcombe \& Robinson, 2000), the informant spontaneously said what she thought about the hidden toy's identity immediately after she had seen or felt it. In Baldwin and Moses' (1996) terminology, children were consumers rather than seekers of knowledge from other people. In real life, however, our potential informants do not necessarily display their knowledge in this way, and we have actively to seek their view to benefit from their experience. To elaborate on the second example in the opening paragraph, having checked the outside temperature I said nothing until you asked me how cold it was. You predict that my answer will be accurate because you know I had the necessary experience, and so you seek my view about the temperature. Do children behave in this way? Does their understanding of the implications of an informant's experience for the likely truth of what she says extend to circumstances in which they need to elicit that person's suggestion?

A first, intuitive assumption might be that the answer to this question is 'Yes'. We know that children actively elicit information from other people by asking questions from the age of around 2 years, and they appear to do so in order to find out about the world. Chouinard's (2007) analysis of children's question-asking episodes in the CHILDES database shows that the majority of questions appeared to seek information (rather than seek permission for example), and repetitions of questions occurred primarily when children did not receive an informative answer. However, children might actively elicit information from others without necessarily understanding the circumstances under which the answers are likely to be accurate. It is widely accepted that children actively explore the physical world, and effectively gain knowledge as a result, without yet understanding what knowledge they can gain from a particular experience. For example, from early infancy, children see and feel objects and thereby discover their colour and hardness, yet many 3- and 4-year-olds cannot predict how they could gain such knowledge nor report how they did gain it (e.g., Gopnik \& Graf, 1988; O'Neill \& Gopnik, 1991; O'Neill, Astington, \& Flavell, 1992; Robinson, Haigh, \& Pendle, 2008; Robinson 
\& Whitcombe, 2003). Something similar could be true for children's ability to gain knowledge indirectly from other people: they may gain knowledge by asking questions prior to understanding how or when they are likely to gain accurate information as a result. The published research does not tell us whether or not this is the case. We aimed to find out in the five experiments reported here.

In each experiment, children aimed to identify which of three possible toys was hidden inside a box. They had not seen inside themselves so could only guess, but on some trials they could correct their guess by relying on the suggestion of an informant who had seen inside. Tasks differed in what children had to do to receive the other's suggestion. In our least demanding task (the show condition in Experiment 1), the child guessed what was in the box and then the informant looked or did not look inside the box and immediately made available to the child her suggestion about its content by marking a picture. Children had the opportunity to change their guess in line with this suggestion. Based on previous research (e.g., Robinson et al., 1999), we expected children to change more frequently when the informant had seen inside the box than when she had not. In the tasks, we expected to be more demanding, the child had actively to seek an informant's suggestion. In the seek condition in Experiments 1, 2, and 3, the informant's marked picture was hidden behind a barrier and the child had to act to consult it. Children knew that the informant had marked a picture, but would they realize that by consulting it they could learn from the informant's experience? Would children consult the picture and change their guess more frequently when the informant had seen inside the box than when she had not seen? Finally, in the various ask conditions in Experiments 2, 4, and 5, the informant (experimenter or puppet) looked or did not look inside the box, but then did nothing unless the child actively elicited her suggestion. Would children more frequently elicit a suggestion, and change their guess, when the informant had seen inside the box than when she had not?

In summary, the informant could make her suggestion available to the child (show), produced a suggestion that the child could decide to consult (seek), or produced no suggestion unless the child elicited it (ask). In each case, we examined whether children were more likely to learn from the informant when she had seen inside the box than when she had not. That is, did they behave in a way consistent with understanding that they could gain knowledge from someone who had the experience they lacked, but not from someone who shared their own position of ignorance?

\section{EXPERIMENT I}

In the first experiment, we aimed to discover whether children were appropriately flexible in their trust in the informant's suggestions. Sometimes the informant's suggestion was manifestly based on relevant experience, sometimes it appeared to be just a guess. If children's trust is appropriately flexible they should more frequently treat suggestions as accurate when the informant manifestly has relevant experience than when she appears to be guessing.

To examine the influence of informant experience, we used two different conditions. In the show condition, children could hardly avoid being aware of the informant's suggestion, and simply had to decide whether or not to trust it. In the seek condition, children had to act to consult the informant's suggestion: they had to stand up to look over a barrier to see the informant's pictorial record. Would children look over the barrier more often when the informant had relevant experience; that is, had seen inside the box? 


\section{Method}

\section{Participants}

Fifty-four nursery children aged 3;2-4;1 (M=3;8, 31 girls), 55 children in their first year of formal schooling (Reception) aged 4;2-5;1 ( $M=4 ; 8,28$ girls), and 41 children in their second year of formal schooling (Yr1) aged 5;2-6;1 ( $M=5 ; 7,26$ girls) participated. In this and the subsequent experiments, children came from mixed middle and working class neighbourhoods in the midlands of England, were predominantly white, and spoke English as their first language. No child took part in more than one experiment.

\section{Materials}

We used three sets of three toys: cat, ladybird, fish; teddy, zebra, man; squirrel, duck, cow. For each set, there were three corresponding strips of photographs showing all three toys, and identical boxes to contain each toy. There were surreptitious tactile marks on the underside of the boxes so that the informant could secretly identify the contents of any box without looking inside. Small bricks of different colours were used as markers, a bag was used for shaking boxes, and a cardboard file was used as a barrier. Finally, a hand puppet, Smoot, was also used.

\section{Design}

We used a $2 \times 2$ design, with informant suggestion (seek, show) as a betweensubjects variable and informant experience (knowledgeable, ignorant) as a withinsubjects variable.

\section{Procedure}

The seek and show conditions differed only in the location of the informant's strip of photographs. On show trials, the informant's photographs were in full view. On seek trials, they were hidden behind a barrier and children had to stand up and look over the barrier to see them. Children were first introduced to one set of toys and accompanying photographs, and were encouraged to match each toy to its photograph. Each toy was then hidden in an identical box, and the boxes were placed in the bag together. Children were then introduced to Smoot and the procedure for placing a marker to indicate their answer was explained.

On each of the two warm-up trials, a box was selected at random from the bag. On the first warm-up trial, children witnessed the informant (the experimenter) err whilst ignorant: she announced that she would place her marker without looking in the box, placed her marker (incorrectly, having secretly determined the contents of the box), and encouraged children to look over the barrier to see her response. Children were then permitted to look inside the box while the informant covered her eyes, discovered she had erred, and placed their own marker. After the toy was returned to its box, the informant announced, 'Now I have to choose for Smoot. I don't know what's inside the box because I didn't look. But you did look, didn't you? So, if Smoot's going to get the right answer, he should choose the same thing as you. I'm going to look at your answer'. The informant identified the location of the child's marker, very obviously looking over the barrier in the seek condition to do so, and placed Smoot's marker in the same position on his photographs, saying, for example, 'Oh, you picked the teddy! Well, then, I'll pick the teddy for Smoot, too!' The box was then opened and the contents verified. 
On the second warm-up trial, children had the experience of not knowing the contents of the box but having to guess, and seeing the informant correctly identify the toy while she was knowledgeable. After the box was selected from the bag, in the manner described above, children were asked to guess its contents without seeing inside. The informant then announced that she would look in the box and that the child should cover his or her eyes while she did so. If the child had happened to guess correctly, the informant secretly switched boxes so that the child would be shown to be wrong. The informant then announced, 'Now I know what's inside the box, and I'm going to put my answer down'. The child was encouraged to put a marker down for Smoot. In the seek condition, the child was additionally encouraged to look over the barrier to see the informant's response. All children were told, 'I've had a look inside, so I know the right answer. So if Smoot wants to get it right, he should choose the same as me!' The box was then opened and the contents verified.

Following the warm-up trials, children received four test trials and one filler trial. All children received one informant ignorant and one informant knowledgeable trial before the filler, and another of each after the filler. The informant ignorant and knowledgeable trials were in the same order before and after the filler, and which came first (ignorant or knowledgeable) was counterbalanced between children. The first two test trials and the filler trial used the second set of toys (fish, cat, ladybird) and the last two test trials used the last set of toys (squirrel, duck, cow). On each test trial, one box was selected at random and placed on the table. Children were encouraged to guess its contents and place their marker accordingly. On ignorant trials, the informant said, 'This time, I'm not going to see inside the box, I'm just going to guess. Okay, I've put down my answer!' On knowledgeable trials, the informant said, 'this time, I'm going to have a look. Okay, I've had my look, and I've put down my answer!' The informant managed the boxes and her own responses so that on ignorant trials she was always incorrect, and on knowledgeable trials she was always correct while the child was incorrect. On all trials, after the informant had placed her marker, children were encouraged to place the marker for Smoot: 'If Smoot wants to get the right answer, where should he put his brick?' After the child placed a marker for the puppet, the box was opened and the contents verified.

The filler trial was a repeat of the first warm-up trial. This served to allow children to have a turn looking in the box, and to remind them of the procedure. We judged that acting on behalf of a third party, Smoot, would make it easy for children to change their initial guess without losing face.

\section{Results and discussion}

\section{Frequency of matching the informant's suggestion}

Children's selection for the puppet could be the same as they had chosen for themselves, the same as the informant's (the experimenter's) suggestion, or they could choose the third object. The third object was in fact chosen very rarely. If children treated the informant's suggestion as accurate, they should match it. More frequently matching the informant's suggestion when she was knowledgeable than when she was ignorant is consistent with child sensitivity to the informant's knowledge state. Thus, children gained a score each time they matched the informant's suggestion, resulting in scores out of 2 for the informant knowledgeable trials and informant ignorant trials. Table 1 shows the mean scores for each trial type in the show and seek conditions. Note that the matching scores in the show and seek conditions are not strictly comparable 
Table I. Experiment I. Mean (SD) incidence of matching informant's response (Max. $=2$ )

\begin{tabular}{lccrcr}
\hline & \multicolumn{2}{c}{ Show condition } & & \multicolumn{2}{c}{ Seek condition } \\
\cline { 2 - 3 } Age group & $\begin{array}{c}\text { Informant } \\
\text { knowledgeable }\end{array}$ & $\begin{array}{c}\text { Informant } \\
\text { ignorant }\end{array}$ & & $\begin{array}{c}\text { Informant } \\
\text { knowledgeable }\end{array}$ & $\begin{array}{c}\text { Informant } \\
\text { ignorant }\end{array}$ \\
\hline Nursery & $1.15(.86)$ & $.52(.70)$ & & $.85(.72)$ & $.33(.56)$ \\
Reception & $1.65(.69)$ & $.50(.71)$ & & $1.07(.70)$ & $.28(.53)$ \\
Yrl & $1.63(.68)$ & $.58(.77)$ & & $1.32(.78)$ & $.50(.67)$ \\
\hline
\end{tabular}

since in the seek condition children might have matched the informant's response by chance, without having looked at it, whereas we assume that was unlikely in the show condition. We explain below why it is nevertheless interesting to compare the incidence of matching between show and seek conditions.

We conducted a mixed model analysis of variance (ANOVA) on the scores, with informant experience (knowledgeable, ignorant) as a within-subjects factor, and age (Nursery, Reception, Yr1) and informant suggestion (show, seek) as between-subjects factors. There was a significant effect of informant experience, $F(1,144)=130.05, p<$ $.001, \mu_{\mathrm{p}}^{2}=.48$, with higher scores when the informant was knowledgeable. There was also a significant effect of age, $F(2,144)=3.47, p=.034, \mu_{\mathrm{p}}^{2}=.05$. Post boc Bonferroni tests showed that it was only the difference between Nursery and Yr1 that was significant, adjusted $p=.036$. Finally, there was also a significant effect of show versus seek, $F(1,144)=9.76, p=.002, \mu_{\mathrm{p}}^{2}=.06$ : children had higher scores in the show than the seek condition.

The interaction between age and informant experience was significant, $F(2,144)=$ $3.29, p=.04$. This interaction arose because there was a greater impact of informant experience for the older children than the younger ones. Nevertheless, when the Nursery children were considered alone, the difference between informant knowledgeable and informant ignorant trials remained significant: $F(1,52)=22.55, p<.001, \mu_{\mathrm{p}}^{2}=.30$. No other effects or interactions approached significance.

While children's matching of the informant's suggestion could have been due to chance in the seek condition (both knowledgeable and ignorant trials), it is noteworthy that the extent to which children differentially endorsed the knowledgeable and the ignorant informant was similar in both the seek and show conditions: there was no interaction between informant experience and show versus seek. The result for the show condition is in line with earlier research involving oral suggestions rather than marked pictures (e.g., Robinson et al., 1999). The new finding is that children were also sensitive to the informant's knowledge in the seek condition. Combining across the age groups, children matched the informant's picture when choosing for Smoot on average .37 times when the informant was ignorant, but 1.08 times when she was knowledgeable.

In both the show and the seek conditions, then, children relied more frequently on the informant's suggestion when she had seen inside the target box than when she had not. Children behaved as if they understood that they could gain knowledge by relying on someone who had the experience they lacked, but not from someone who shared their own position of ignorance.

\section{Seek condition: Moving to consult the informant's suggestion}

In the seek condition, we also examined whether children moved to look at the informant's marked photograph more frequently when she was knowledgeable rather 
Table 2. Experiment I. Seek condition. Mean (SD) incidence of looking around barrier to see informant's response (Max. $=2$ )

\begin{tabular}{lcc}
\hline Age group & Informant knowledgeable & Informant ignorant \\
\hline Nursery & $.70(.82)$ & $.26(.53)$ \\
Reception & $.90(.86)$ & $.17(.47)$ \\
Yrl & $1.18(.96)$ & $.27(.55)$ \\
\hline
\end{tabular}

than ignorant. Children might have looked over the barrier regardless, but been selective in their use of what they saw. If so, this would be similar to asking a question of an ignorant informant but then disregarding the answer, as opposed to asking a question only when the informant was knowledgeable. Children in the seek condition were given a further two scores out of 2 , based on the number of times they moved to look over the barrier at the informant's marked photograph. The gross body movement required meant there was no risk of unreliable coding. The mean scores appear in Table 2. Scores were entered into a mixed model ANOVA with informant experience as a withinsubjects factor (knowledgeable, ignorant) and age group as the between-subjects factor. There was a significant main effect of informant experience, $F(1,75)=62.5, p<.001$ : children looked over the barrier more frequently when the informant was knowledgeable than when she was ignorant. No other effects or interactions were significant or near significant.

Hence, in both the show and the seek conditions, children used the informant appropriately as a source of knowledge based on her experience. They behaved as if they understood that they could learn the content of the target box by consulting the informant's marked photograph, so long as she had seen inside the box. There was agerelated improvement, but even the 3-to 4-year-olds showed sensitivity to the informant's relevant experience of seeing inside the box. This was the case even when children had to look over the barrier to see the informant's marked photograph. In Experiment 2, we created an even more demanding condition in that children had to act not just to consult the informant's suggestion, but to elicit it.

\section{EXPERIMENT 2}

In Experiment 2, we introduced an ask condition in which there was no photograph of the informant's suggestion for the child to consult. Instead, children could ask the informant for help via a toy mobile phone, whereupon she told them what she thought was in the target box. A comparison seek condition was the same as that used in Experiment 1 . In both conditions, the child merely had to make a simple physical movement to find out what the informant thought was in the target box, raising the toy phone to her ear (without saying anything), or standing up to look over the barrier. The conditions differed in that the physical movement in seek amounted to consulting a suggestion already made, whereas in ask the physical movement amounted to eliciting a suggestion. Given the results of Experiment 1, we expected that in the seek condition, children would more frequently elicit a suggestion and change their guess when the informant had seen inside the box than when she had not. Would they also do so in the new ask condition? We used a toy phone in the ask condition for two related reasons. First, the simple physical act of raising the phone to the ear was comparable to the act of standing up to look over the barrier: it would be implausible to argue that children 
could succeed at one yet fail at the other. Second, children did not face the demands of having to formulate a question, or even say anything.

\section{Method}

\section{Participants}

Fifty-five children in their first year of formal schooling participated. They were aged $4 ; 4-5 ; 3$ ( $M=4 ; 9,27$ girls). This was the middle age group (Reception) from Experiment 1 , and judged to be the most useful for comparing the new ask condition against the seek condition. As a precaution against a lower overall frequency of help-seeking in the ask condition than in the seek condition, we entered relatively more children into the ask condition to avoid floor effects (a precaution that turned out to be unnecessary). The ask condition had 32 children, and the seek condition had 23.

\section{Materials}

These were the same as in Experiment 1, except that to speed up the procedure, we used only one set of three toys (squirrel, duck, cow). After each trial, the toys were returned to their boxes, placed in the bag and shaken, and children were warned that it might be the same toy again on a subsequent trial.

\section{Design}

We used a $2 \times 2$ design, with informant suggestion (seek, ask) as a between-subjects variable and informant experience (knowledgeable, ignorant) as a within-subjects variable.

\section{Procedure}

The seek and ask conditions differed in whether the informant (the experimenter) had a strip of photographs of her own. The seek condition was the same as in Experiment 1. In the ask condition, the warm-up trials and test trials were modified appropriately. The child and informant both had toy mobile phones and the child could 'ring' the informant. The informant did not have a set of photographs, but instead gave an oral response when the child raised the phone to her ear. On the first ask warm-up trial, children witnessed the informant err whilst ignorant: she announced that she would have a guess without looking in the box. The informant placed her marker, then encouraged children to use the mobile phone to ring her to hear her answer. She always gave an incorrect response, having secretly determined the contents of the box. Children were then permitted to look inside the box while the informant covered her eyes, discovered that the informant had erred, and placed their own marker. After the toy was returned to its box, the informant announced, 'Now I have to choose for Smoot. I don't know what's inside the box, because I didn't look. But you did look, didn't you? So if Smoot's going to get the right answer, he should choose the same thing as you. I'm going to ring you to find out your answer'. The informant pretended to ring the child, asking, 'What do you think is in the box?' and placed Smoot's marker on in the same position on his photographs, saying, for example, 'Oh, you picked the teddy! Well, then, I'll pick the teddy for Smoot, too!' The box was then opened and the contents verified.

On the second warm-up trial, children had the experience of not knowing the contents of the box but having to guess, and witnessing the informant correctly identify 
the toy when she was knowledgeable: after the box was selected from the bag, children were asked to guess its contents without seeing inside. The informant then announced that she would look in the box and that the child should cover his or her eyes while she did so. If the child had happened to guess correctly, at this point, the informant secretly switched boxes so that the child would be shown to be wrong. The informant announced, 'Now I know what's inside the box'. Children were encouraged to use the toy phone to ring the informant. All children were told, 'I've had a look inside, so I know the right answer. So if Smoot wants to get it right, he should choose the same as me!' The box was then opened and the contents verified.

As in Experiment 1, children then received one informant ignorant and one informant knowledgeable trial with the order counterbalanced between children, followed by a filler trial, then a second informant ignorant and a second informant knowledgeable trial in the same order as their first pair.

\section{Results and discussion}

Children gained a score each time they sought information from the informant (the experimenter). Children in the seek condition gained a score by looking over the barrier at the informant's choice, and children in the ask condition gained a score by raising the toy phone to their ear. Hence, each child received two scores out of 2 according to the number of times they sought help from the informant when she had seen the target toy (knowledgeable) and when she had not (ignorant). Since children always acted in accordance with the information they obtained from the informant, there was no need to analyse the matching scores in addition to the help-seeking scores.

In the ask condition, when the informant was knowledgeable, the mean score was .50 $(S D=.80)$, and when she was ignorant it was $.31(S D=.69)$. The corresponding mean scores for the seek condition were $.96(S D=.88)$ and $.17(S D=.39)$, respectively. Scores were entered into a mixed model ANOVA, with informant experience (knowledgeable, ignorant) as a within-subjects factor, and informant suggestion (ask, seek) as a betweensubjects factor. There was a main effect of informant experience, $F(1,53)=29.29$, $p<.001, \mu_{\mathrm{p}}^{2}=.36$. The main effect of ask versus seek was not significant $(p=.37)$. Importantly, the interaction between informant experience and informant suggestion (ask vs. seek) was significant, $F(1,53)=11.02, p=.002$. Examination of the interaction showed that it was due to greater differentiation between the informant knowledgeable and informant ignorant trials in the seek condition than in the ask condition. Pairedsamples $t$-tests showed that, for the seek condition, the difference between trial types was clearly significant, $t(22)=-4.72, p<.001$. By contrast, the difference between trial types was only marginally significant for the ask condition, $t(31)=-1.98, p=$ .056. Thus, although the overall incidence of information seeking was no greater in the seek condition than in the ask condition, in the seek condition, children's information seeking varied strongly with the informant's experience. In the ask condition, children's information seeking was only marginally influenced by the informant's experience.

It is important to note that it is only the difference between informant knowledgeable and informant ignorant trials that is of interest. We can infer nothing from absolute scores since there was nothing wrong in phoning for help when the informant was ignorant (although there was additional reason for phoning when she was knowledgeable), and children's willingness to elicit information from the informant will be influenced by social factors such as her perceived friendliness. However, in the seek condition, unlike the ask condition, children consulted the informant's suggestion more often when she 
was knowledgeable rather than when she was ignorant. The contrast between children's sensitivity to the informant's experience in seek condition, and their relative insensitivity in ask condition, suggests that we have begun to identify the limits of children's effective use of the informant as a source of knowledge. It is this suggestion that we pursue in the subsequent studies.

Why were children in the ask condition only marginally more likely to seek help from the informant when she had seen inside the target box than when she had not, whereas children in the seek condition were much more likely to do so? The ask and seek conditions differed in whether or not children had to elicit the informant's suggestion, so we assume this is the relevant factor. In Experiment 3, therefore, we aimed to further clarify just why children failed to elicit information more frequently from a knowledgeable than an ignorant informant.

\section{EXPERIMENT 3}

In Experiment 3, we introduced a new ask-to-see condition and compared it to the seek condition. In both conditions, the informant (the experimenter) placed a block on one of a set of photographs to record her suggestion behind a barrier. In the ask-to-see condition, however, instead of standing up to look over the barrier, children raised a toy mobile phone to their ear without having to say anything, indicating that they wanted the informant to lift the barrier for them to see. Hence, as in the ask condition of Experiment 2, children had to perform a simple act using the toy phone, and they also had to engage in the pretense of using the toy phone. The only difference was that in the ask-to-see condition, the informant had already produced a pictorial record by the time the child decided to ask. We examined whether children would ask to see the informant's marked picture more frequently when she had seen inside the target box than when she had not. If so, we could conclude that the need to ask for help was not in itself a problem, and that children were not somehow confused by our use of the toy mobile phone. We could infer that children's apparent insensitivity to the informant's experience in the ask condition (Experiment 2) arose because it was their asking that elicited the informant's suggestion.

\section{Method}

\section{Participants}

As in the previous Experiments, we included children in their first year of formal schooling (Reception). There were 49 children aged 4;8-5;7 ( $M=5 ; 2,25$ boys), and, as in Experiment 1, we included an older age group of 51 children in their second year of formal schooling (Yr1) aged 5;8-6;7 ( $M=6 ; 2,16$ boys).

\section{Materials}

These were the same as in Experiment 2.

\section{Design}

We used a $2 \times 2$ design, with informant suggestion (seek, ask-to-see) as a betweensubjects variable and informant experience (knowledgeable, ignorant) as a withinsubjects variable. 
Table 3. Experiment 3. Mean (SD) incidence of seeking further information in the ask-to-see and seek conditions (Max. $=2)$

\begin{tabular}{lccccc}
\hline & \multicolumn{2}{c}{ Ask-to-see condition } & & \multicolumn{2}{c}{ Seek condition } \\
\cline { 2 - 3 } Age group & $\begin{array}{c}\text { Informant } \\
\text { knowledgeable }\end{array}$ & $\begin{array}{c}\text { Informant } \\
\text { ignorant }\end{array}$ & & $\begin{array}{c}\text { Informant } \\
\text { knowledgeable }\end{array}$ & $\begin{array}{c}\text { Informant } \\
\text { ignorant }\end{array}$ \\
\hline Reception & $.58(.78)$ & $.29(.69)$ & & $.72(.79)$ & $.32(.63)$ \\
Yrl & $.85(.83)$ & $.31(.610)$ & & $.96(.89)$ & $.60(.91)$ \\
\hline
\end{tabular}

\section{Procedure}

The procedure for the seek condition was the same as in Experiments 1 and 2. In the ask-to-see condition, children had to raise a toy mobile phone to their ear if they wanted the informant to raise the barrier for them to see her marked photograph. Warm-up and test trials were modified appropriately.

\section{Results and discussion}

Children were given a score of 1 each time they looked over the barrier (in the seek condition) or raised the mobile phone to their ear (in the ask-to-see condition). The results are summarized in Table 3. We conducted an ANOVA with informant experience (knowledgeable vs. ignorant) as a within-subjects factor, and informant suggestion (seek vs. ask-to-see) and age group (Reception vs. Yr1) as between-subjects factors. There was a main effect of informant experience, $F(1,96)=23.26, p<.001, \mu_{\mathrm{p}}^{2}=.45$. There were no other significant main effects or interactions.

As mentioned in connection with Experiment 2, the absolute level of seeking help will vary with social factors such as the informant's perceived friendliness or helpfulness; it is the relative incidence of seeking help according to her knowledge or ignorance that is important for our research question. In Experiment 3, children in both age groups and in both conditions used the informant appropriately as a source of knowledge: children sought help more frequently when the informant had seen inside the target box than when she had not. There was no difference according to whether children gained knowledge by looking over the barrier at the informant's marker, or by phoning to ask the informant to raise the barrier for them to see. This suggests that the relative insensitivity to the informant's experience in the ask condition of Experiment 2 was not due to difficulty with the act of asking via the toy phone per se. Rather, we argue, children were insensitive to the informant's experience in the ask condition precisely because it was their asking that elicited the informant's suggestion. In the final discussion, we elaborate on why this could have been the source of children's difficulty. First, however, we aimed to narrow down still further the conditions under which children are insensitive to a potential informant's relevant experience. In Experiment 4, we examine whether children can take into account the informant's experience when there is no need for them to make a decision whether or not to ask for help.

\section{EXPERIMENT 4}

In all the experiments so far we have examined children's appropriate flexibility in their trust in an informant's suggestion: when the informant had looked inside the target box there was an additional reason to trust the accuracy of her suggestion compared 
to when she had not looked. Results show that children were appropriately flexible in their trust in an informant's suggestion when it was offered spontaneously, even if the child had to act to consult it (as in the seek condition of Experiments 1, 2, and 3), and even if the act involved asking for help (as in the ask-to-see condition of Experiment 3 ). In all these conditions, children were more likely to trust a suggestion made when the informant had relevant experience than a suggestion made when the informant shared the child's position of ignorance. In contrast, when children had to elicit the informant's suggestion, as in the ask condition of Experiment 2, they apparently failed to spot the implications of her relevant experience, and were not significantly more likely to trust her suggestion when she had seen inside the target box than when she had not.

In Experiment 4, we examined the possibility that children sometimes fail to spot the implications of an informant's relevant experience in part because they have to decide whether or not to elicit a suggestion. Is it easier for children to take into account the implications of an informant's relevant experience when they do not need to decide whether to elicit a suggestion?

To answer this question, we introduced a new who-to-ask condition in which children were required to ask one of two puppets, only one of which had seen inside the target box. In a comparison whether-to-ask condition, children had the choice of guessing for themselves or asking for help, similar to the ask condition in Experiment 2 . In the who-to-ask condition, children did not have to make a decision whether or not to ask for help. If it is the need to make such a decision that causes children's difficulties with the ask condition of Experiment 2, then they should have no such difficulties in the who-to-ask condition.

In both the whether-to-ask and who-to-ask conditions, there were two puppets, only one of whom had the relevant experience to inform the child. Having this contrast between a knowledgeable and an ignorant puppet within each trial might make more obvious the implications of the informant's relevant experience. We might find, therefore, that children performed relatively well even in the whether-to-ask condition. A related consequence of having two puppets was that on every trial the best way to identify the target toy correctly was by asking the informant who had seen inside the target container. Whereas in the previous experiments, there was no inherent disadvantage in relying on the ignorant informant (although in fact children tended not to do so in the show, seek, and ask-to-see conditions), in Experiment 4, it was wrong to ask the ignorant informant.

\section{Method}

\section{Participants}

We tested 30 children in their first year of formal schooling (Reception), aged 4;3-5;2 ( $M=4 ; 71,11$ boys) and 30 children in their second year of formal schooling (Yr1), aged 5;3-6;2 ( $M=5 ; 81$ years, 17 boys).

\section{Materials}

These were the same as in Experiment 2, with the addition of a pencil case used as an alternative object for the puppets to look at, and four puppets: two teddy bears and two dogs were used as the potential informants. The puppets had easily remembered names, for example 'Brown bear' and 'White bear'. Which condition (who-to-ask or whether-toask) had bears and which had dogs was counterbalanced between participants. 


\section{Design}

We used a $2 \times 2$ design, with informant suggestion (who-to-ask, whether-to-ask) as a between-subjects variable and informant experience (knowledgeable, ignorant) as a within-subjects variable.

\section{Procedure}

The toys, their photographs, and the boxes were introduced as in the previous experiments, and children matched each toy to its photograph. The photographs were present throughout to remind the child of the possible contents of the target box. Each condition began with a warm-up followed by two test trials. In the who-to-ask warm-up, the children were asked to show one puppet the content of the target box and the other puppet the pencil case. The experimenter then modelled asking the knowledgeable puppet for help, saying. 'I don't know what is in the box but I am going to ask (name of bear/dog) to help me because he has seen in the box. Can you make the voice of the bear/dog telling me what he has seen in the box?' After the child had done this, the experimenter said '(Bear/dog) had looked in the box and said it was (name of toy) so I'm going to say (name of toy). Can you open the box and see what is in it?' The box was then opened and the contents verified.

In the two subsequent who-to-ask test trials, the experimenter let one puppet see inside the target box and the child showed the other puppet the contents of the pencil case. The experimenter then said, 'You need to say what is in the box but a (bear/dog) will always help you. You can ask one of the (bears/dogs) to help you. Which one do you want to ask?' The child then indicated a puppet and the experimenter made the voice of the bear/dog saying what was in the box, giving the correct answer if it had looked in the box or the incorrect answer if it had looked in the pencil case. The child was then asked, 'So what's in the box?' and box was then opened and the contents verified. For the other condition, the puppets were exchanged.

The whether-to-ask warm-up and test trials were similar, but modified to suit the choices available to the child on her test trials. On these, the experimenter said, 'You are allowed to make your own guess or you can ask a bear/dog to help you - remember one of them has seen which toy is in the box. What would you like to do, make your own guess or ask a bear/dog?' The order of choices was counterbalanced. Children who chose to ask nearly always spontaneously indicated which bear/dog they wanted to ask. The experimenter made the voice of the puppet saying what was in the box, as in the who-to-ask trials. The child was then prompted, 'So what's in the box?' The box was then opened and the contents verified.

\section{Results and discussion}

First, we analysed the frequency with which children asked for help in the whether-toask condition. A univariate ANOVA showed that older children more frequently guessed, without asking a puppet for help: 4- to 5-year-olds asked a toy on a mean of 1.67 (SD = .62) trials, whereas 5 - to 6-year-olds asked on a mean of $1.14(S D=.66)$ trials, $F(1,28)=$ $4.86, p=.04, \mu_{\mathrm{p}}^{2}=.15$. Although it was unexpected that older children guessed more often than younger children, for our purposes what is important is that children in both age groups asked for help sufficiently often for us to examine their preference for the knowledgeable puppet over the ignorant one.

On every trial, the child could ensure she correctly identified the contents of the target box by asking the puppet that had looked inside. Children gained a score of 1 
each time they asked the knowledgeable puppet and then repeated that puppet's answer when asked, 'So what's in the box?' (Maximum score $=2$ ). Since in the whether-to-ask condition children had the choice of guessing for themselves without asking the puppet, for both conditions we then divided each child's score by the number of trials on which they asked for help, yielding a proportional score. Two younger and two older children who never asked for help in the whether-to-ask condition were omitted from the analysis.

We entered the proportional scores into an ANOVA with age group (Reception, Yr1) and informant suggestion (who-to-ask, whether-to-ask) as between-subjects factors. The mean proportional scores for the younger children were $.63(S D=.40)$ for who-to-ask, and $.50(S D=.44)$ for whether-to-ask. The corresponding scores for the older children were $.69(S D=.40)$ and $.75(S D=.40)$, respectively. Neither the interaction nor the main effects were significant.

We then compared children's proportional scores against the frequency distribution expected by chance. The 4- to 5-year-olds' performance was no different from chance in either condition: whether-to-ask condition, $p=.27$; who-to-ask condition, $p=.15$. In contrast, the 5- to 6-year-olds were above chance at asking the knowledgeable puppet in both conditions: whether-to-ask condition $\chi^{2}(2)=11.33, p=.003$; who-to-ask condition $\chi^{2}(2)=8.50, p=.01$. That is, despite the absence of a significant effect of age in the ANOVA, the older children did ask the knowledgeable puppet more frequently than chance in both conditions, whereas the younger ones did not.

Hence, despite the fact that children witnessed the contrast between the knowledgeable and the ignorant puppet on each trial, the younger children seemed to ignore the relevance of one puppet having seen inside the target box for gaining knowledge of its content themselves. The lack of difference in performance between the who-to-ask and whether-to-ask conditions suggests that children's difficulty was not due to having to decide whether to ask for help or guess for themselves. Even when they were required to ask one of the puppets for help, the younger children were no better than chance at asking the puppet with the relevant experience.

Younger children's poor performance is particularly striking given the similarity of the who-to-ask procedure to that used by Koenig and Harris (2005) in their work on children's sensitivity to an informant's past accuracy. In their tasks, children were required to ask one of two potential informants the name of a novel object. Four-yearolds consistently preferred the one who had previously named familiar objects accurately over the one who had previously named them inaccurately. Of course we cannot make firm comparisons across samples, but the implication is that young children find it easier to identify an informant as knowledgeable on the basis of previous accuracy, than to treat an informant as knowledgeable by virtue of her recent access to relevant information.

\section{EXPERIMENT 5}

In the final experiment, we checked whether children were confused by the procedure in Experiment 4. We compared the who-to-ask condition with a new condition in which children merely judged which of the two puppets knew what was in the target box, the one who had seen inside the box, or the one who had seen inside the pencil case. The published literature leads us to expect that by 4 years of age, most children will make their judgements in keeping with the principle that 'seeing equals knowing', and so should answer correctly in this task (e.g., Pillow, 1989). If they do not, this might suggest that the procedure was confusing and that perhaps children forgot which puppet had 
the relevant experience. On the other hand, if children judged correctly which puppet knew the box's content when simply judging knowledge, yet in the who-to-ask condition failed to ask the knowledgeable puppet what was in the box, this could suggest some weakness in their understanding about knowledge transfer between minds.

\section{Method}

\section{Participants}

We tested 30 children in their first year of formal schooling (Reception), aged 4;4-5;3 ( $M=4 ; 10,12$ boys), and 30 children in their second year of formal schooling (Yr1), aged 5;4-6;3 ( $M=5 ; 9,18$ boys).

\section{Materials}

These were the same as in Experiment 4.

\section{Design}

The design was $2 \times 2$ with informant suggestion (who-to-ask, who-knows) as a withinsubjects variable and age (Reception, Yr1) as a between-subjects variable.

\section{Procedure}

Children had two who-to-ask trials followed by two who-knows trials, or vice versa, with the order alternating between children. The who-to-ask warm-up and test trials were as in Experiment 4. There was no warm-up for the who-knows test trials. On these, after the experimenter had let one puppet look in the target box and the child let the other puppet look in the pencil case, the child was asked, 'Which bear/dog knows what's in the box?' followed by, 'What do you think is in the box?' After the child had guessed, the box was opened and the answer verified.

\section{Results and discussion}

Each child gained a score of 1 each time she asked the knowledgeable puppet and repeated that answer in the who-to-ask trials, maximum score 2, and a score of 1 for each correct answer in the who-knows trials, maximum score 2 . Results were entered into a mixed model ANOVA with informant suggestion (who-to-ask, who-knows) as a withinsubjects factor, and age group (Reception, Yr1) and order of trial type presentation as between-subjects factors. The only significant difference was for informant suggestion, $F(1,56)=8.23, p=.006, \mu_{\mathrm{p}}^{2}=.13$. Children performed better on the who-knows trials. For Nursery children, the mean scores were $1.37(S D=.77)$ and $1.57(S D=.73)$ on the who-to-ask and the who-knows trials, respectively. For Yr1 children, the respective mean scores were $1.23(S D=.86)$ and $1.70(S D=.60)$.

In both age groups, on the who-to-ask trials approximately half the children asked the knowledgeable puppet on both trials (53\% in Reception and 50\% in Yr1). In contrast, on the who-knows trials, $70 \%$ of Nursery children and $77 \%$ of Yr1 children correctly identified the knowledgeable puppet as knowledgeable on both trials. Despite the relatively poor performance on the who-to-ask trials, both age groups performed above chance on both trial types: 4 - to 5 -year-olds, who-to-ask, $\chi^{2}(2)=12.87, p=.002 ; 4$ - to 5- year-olds who-knows $\chi^{2}(2)=32.60, p<.001$. Children 5- to 6-year-olds, who-to-ask, $\chi^{2}(2)=11.80, p=.003 ; 5$ - to 6-year-olds who knows $\chi^{2}(2)=42.73, p<.001$. These 
results confirm that children's relatively poor performance on the who-to-ask trials was unlikely to be due to their forgetting which puppet had seen inside the target box. Rather, children appear to be struggling to see the relevance of the puppets' knowledge within an interrogative context despite the fact that they find it relatively easy to report that the puppets know on the basis of having seen.

\section{GENERAL DISCUSSION AND CONCLUSIONS}

Our aim was to examine children's understanding that they could gain knowledge indirectly from someone who had seen something they had not. We found a contrast between cases in which an informant's suggestion was made uninvited and cases in which children had to elicit the informant's suggestion. Where an informant's suggestion was made uninvited, even if it was hidden from the child, children readily took into account the informant's experience in evaluating the likely truth of her suggestion (the show and seek conditions of Experiments 1-3 and the ask-to-see condition of Experiment 3 ). But children less frequently took into account the informant's experience when the suggestion was not made unless or until the child requested it, that is, in the ask condition of Experiment 2, and the who-to-ask and whether-to-ask conditions in Experiments 4 and 5. In these cases, children were no less likely to elicit information when the informant shared their own position of ignorance than when the informant had the experience they lacked. In short, although children are generally sensitive to an informant's experience when deciding whether to consult and accept her spontaneously made suggestion, they are less likely to show such sensitivity when they have to elicit the suggestion themselves.

We can discount the possibility that lack of sensitivity to the informant's experience in the ask conditions had anything to do with the missing content of the suggestion, since in the seek condition, the suggestion was hidden from the child at the time she decided whether or not to consult it, and in any case, the content itself was completely uninformative about its truth. Even if the presence of the marked picture somehow helped children identify what the experimenter thought was in the target box [as did the thought bubbles with much younger children in Wellman, Hollander, \& Schult's, (1996) study], this would not be sufficient for them to evaluate the likely truth of the experimenter's belief.

We can also discount the possibility that the social context somehow misled children into thinking the experimenter could help them on informant ignorant trials: the warmup trials used in Experiments 1, 2, and 3 meant both that children were shown the value of seeking help on informant knowledgeable trials, and that there were no prompts on the test trials themselves to suggest that the ignorant experimenter could provide them with the correct answer. In the seek and ask-to-see conditions, the informant made her response potentially available both when she was knowledgeable and when she was ignorant, yet children readily differentiated appropriately between these trial types. That is, whilst the informant might have appeared to be more helpful in the seek and ask-to-see conditions than in the ask condition (in that she made her suggestion without the child having to elicit it), she appeared similarly helpful whether she was ignorant or knowledgeable. Yet children were not misled by helpfulness of the ignorant informant in the seek and ask-to-see conditions.

What is it, then, about having to elicit a suggestion from a potential informant that makes it more difficult for children to take into account whether or not the informant had seen inside the target box? The key difference between the conditions in which children took the informant's experience into account (the show, seek, and ask-to-see conditions) 
and the conditions in which they did so less frequently (the various ask conditions) lies in the connection between the informant's relevant experience of looking in the target box, and her making her suggestion about the target object. In the show, seek, and askto-see conditions, this connection was unbroken: the informant made her suggestion immediately after looking or not looking inside the target box, even if the child could not immediately see what that suggestion was. This may have made it relatively easy for children to attend to the relevance of the informant's experience for the likely accuracy of her suggestion. In contrast, in the various ask conditions, the connection between the informant's looking or not looking inside the box, and her making her suggestion about the target object, was broken. It was the child's own action of putting the phone to her ear (in Experiment 2) or indicating one of the puppets (in Experiments 4 and 5) that was the immediate cause of the informant's producing her suggestion. As a consequence, children may lose sight of the implications of the informant's experience for the likely truth of the informant's suggestion.

More generally, our suggestion is that when children have actively to elicit knowledge from another person, so that the immediate cause of their providing information is the child's request, children may lose sight of the implications of the other person's relevant experience. That is, 4- to 5-year-olds may fail to realize that whether asking a parent, 'Where's my coat?' yields an accurate answer is likely to depend on whether the parent saw where the coat was left.

This brings us to the relevance to children's everyday life of our findings. Clearly there is no dispute that young children do gain knowledge from others by asking questions (e.g., Chouinard, 2007; Harris 2007a; but see Mills, Legare, Bills, \& Mejias, 2010 for deficiencies in children's question-asking skills). These studies provide no grounds for arguing that the information the children in our experiments were expected to elicit was atypical. The examples given in Chouinard's (2007) analysis of the CHILDES database suggest that asking about the content of the target box, as in our experiments, was not an alien form of question for children aged 3-6 years. Although requests for labels were very common amongst 1 - and 2-year-olds, by 4 to 5 years they accounted for only $13 \%$ of requests, similar to requests about location, $15 \%$. Yet our results suggest that many 4- to 5-year-olds suffer limitations in understanding the process by which they can gain knowledge as a result of asking a question. They may fail to realize that it is by virtue of another person's specific experience that they themselves can gain the knowledge they need. Our results support the possibility raised in the introduction, that children may ask questions without yet fully understanding the circumstances under which they are likely to gain an accurate answer. Having received an answer, of course, conversational pragmatics make it likely children will expect it to be true, and indeed in our experiments, children nearly always acted on the information provided by an ignorant informant.

To return to the example in the opening paragraph of the introduction, the confidence I have in what someone tells me about the content of a box depends on my recognizing that they have had a particular experience, seeing inside the box, that yields the knowledge I seek. By contrast, on many occasions, we confidently gain knowledge from others in ways that depend only on recognizing them as generally knowledgeable. For example, if I want to know the name of an unfamiliar plant, I might consult a friend who has demonstrated knowledge of plant names in the past, without giving any thought to how she might have found out the name of this particular one. My confidence that I can gain knowledge from what she says does not depend on recognizing particular experiences she has had. These examples highlight a difference in the kind of epistemic 
grounds we can have for gaining knowledge via other minds: particular experiences versus general reliability.

To take a developmental perspective, many if not most of the circumstances under which children, as opposed to adults, gain knowledge from other people may be more like the second example than the first. Other people, particularly adults, just know more about many domains, and the precise details of how that knowledge was gained are irrelevant. Children are particularly ready to gain generalisable knowledge from adults and adults are particularly ready to pass on such knowledge to children (Csibra \& Gergely, 2005). Children's evaluations of the likely reliability of what they are told seem to be well suited to this kind of knowledge-gaining circumstance (Harris, 2007b). For example, they learn the name of a novel object from a speaker who previously named familiar objects accurately, rather than from one who previously named them inaccurately for no obvious reason (e.g., Birch, Vauthier, \& Bloom, 2008; Jaswal \& Neely, 2007; Koenig \& Harris, 2005; Pasquini, Corriveau, Koenig, \& Harris, 2007). Yet, like adults, 4-yearolds' effective evaluations of the likely truth of testimony are not confined to such circumstances. They can also be flexible in putting their trust in speakers, treating a speaker as knowledgeable when he has relevant experience, but as ignorant when he has not, as in the show, seek, and ask-to-see conditions in the experiments reported here (see also Nurmsoo \& Robinson, 2009b; Robinson et al., 1999; Robinson \& Nurmsoo, 2009; Robinson \& Whitcombe, 2003; Whitcombe \& Robinson, 2000).

In marked contrast to young children's success at evaluating the likely truth of testimony in all those studies, their limitations became apparent when they had to be proactive in eliciting knowledge from somebody who had the experience they lacked. Yet if children suffered from limited understanding of the process of knowledge transfer between minds, why did they not always guess for themselves? Why did they ask the experimenter for information around half the time? Our suggestion is that children elicit information from others as one way of dealing with uncertainty, just as they explore the physical world without necessarily being able to predict what specific knowledge they will gain from a particular modality of access (e.g., O'Neill et al., 1992). Given that in our tasks, children were explicitly shown how to elicit information from the experimenter, it is not surprising that they often did so. That they did not do so more frequently is likely to be due to the social context; even adults and older children are influenced by the social context when deciding whether or not to seek help (e.g., Nelson-Le Gall, Gumerman, \& Scott-Jones, 1983; Newman, 2000).

The absolute level of seeking information from the experimenter in our procedures (as opposed to differentiation between trials on which the experimenter was knowledgeable and trials on which she was ignorant) would be expected to vary depending on a number of social factors such as how familiar children were with the experimenter, how friendly she seemed, how positively she responded when children had sought information on earlier trials, and so on. Examining the influence of these factors is beyond the scope of the present research and our experiments were not designed to identify it. Rather, we aimed to ensure that such factors did not interfere with our ability to answer the question of interest: 'Do children understand that they can gain knowledge from someone who has the experience they lack?' The interesting and surprising finding from our experiments is not that children sometimes failed to ask for help from the experimenter when she had seen inside the target box, but rather that they asked her no less often when she had not seen inside.

What might be the impact on children in their everyday lives of limited understanding about knowledge transfer? When learning about the world, children are heavily reliant 
on information provided by other people to supplement their own direct experience (e.g., Csibra \& Gergely, 2005; Harris, 2007b). This ability to learn from other people's knowledge and experience obviously brings great benefits, but also has associated risks, since other people can be wrong or can be misunderstood. Often, and particularly with very young children, knowledge transfer is initiated by the more competent other. For unsolicited information, children seem to be quite capable of managing the risks. In general, the findings suggest that many 4-year-olds can balance effectively the benefits of learning what is true against the risks of believing what is false, whether by taking into account the informant's relevant experience as in the studies reported here, or by taking into account the informant's past history of providing accurate information (e.g., Birch et al., 2008; Jaswal \& Neely, 2007; Koenig \& Harris, 2005; Pasquini et al., 2007). However, children do not just wait for others to take the initiative to pass on their knowledge. Children also actively engage the help of potential informants to fill gaps in their knowledge. Our findings suggest that children's skill at doing this may outpace their ability to evaluate the likely reliability of their informants.

\section{References}

Baldwin, D. A., \& Moses, L. J. (1996). The ontogeny of social information gathering. Child Development, 67, 1915-1939.

Birch, S. A. J., Vauthier, S. A., \& Bloom, P. (2008). Three- and four-year-olds spontaneously use others' past performance to guide their learning. Cognition, 107, 1018-1034.

Chouinard, M. (2007). Children's questions: A mechanism for cognitive development. Monographs of the Society for Research in Child Development, 72(1, Serial No. 286).

Csibra, G., \& Gergely, G. (2005). Social learning and social cognition: The case for pedagogy. In M. H. Johnson \& Y. Munakatas (Eds.), Processes of change in brain and cognitive development. Attention and performance XXI (pp. 249-274). Oxford: Oxford University Press.

Gopnik, A., \& Graf, P. (1988). Knowing how you know: Young children's ability to identify and remember the sources of their beliefs. Child Development, 59, 1366-1371.

Harris, P. (2007a). Commentary: Time for questions. Monographs of the Society for Research in Child Development. 72, (pp. 114-120, 1 Serial No. 286).

Harris, P. L. (2007b). Trust. Developmental Science, 10, 135-138.

Jaswal, V. K., \& Neely, L. A. (2007). Adults don't always know best: Preschoolers use past reliability over age when learning new words. Psychological Science, 17, 757-758.

Koenig, M., \& Harris, P. (2005). Preschoolers mistrust ignorant and inaccurate speakers. Child Development, 76(6), 1261-1277.

Mills, C. M., Legare, C. H., Bills, M., \& Mejias, C. (2010). Preschoolers' use questions as a tool to acquire knowledge from different sources. Journal of Cognition and Development, 11, 533-560.

Nelson-Le Gall, S., Gumerman, R. A., \& Scott-Jones, D. (1983). Instrumental help-seeking and everyday problem-solving: A developmental perspective. In B. M. dePaulo, A. Nadler, \& J. D. Fisher (Eds.), New directions in helping, Vol. 2. Help-seeking (pp. 265-283). New York: Academic Press.

Newman, R. S. (2000). Social influences on the development of children's adaptive help seeking: The role of parents, teachers, and peer. Developmental Review, 20, 350-404.

Nurmsoo, E., \& Robinson, E. J. (2009a). Identifying unreliable informants: Do children excuse past inaccuracy? Developmental Science, 11, 905-911.

Nurmsoo, E., \& Robinson, E. J. (2009b). Children's trust in previously inaccurate informants who were well- or poorly- informed: When past errors can be excused. Child Development, 80, 23-27.

O'Neill, D. K., Astington, J., \& Flavell, J. (1992). Young children's understanding of the role that sensory experiences play in knowledge acquisition. Child Development, 63(2), 474-490. 
O'Neill, D. K., \& Gopnik, A. (1991). Young chidren's ability to identify the sources of their beliefs. Developmental Psychology, 27, 390-397.

Pasquini, E. S., Corriveau, K. H., Koenig, M., \& Harris, P. L. (2007). Preschoolers monitor the relative accuracy of informants. Developmental Psychology, 43, 1216-1226.

Pillow, B. H. (1989). Early understanding of perception as a source of knowledge. Journal of Experimental Child Psychology, 47, 116-129.

Robinson, E. J., Champion, H., \& Mitchell, P. (1999). Children's ability to infer utterance veracity from speaker informedness. Developmental Psychology, 35, 535-546.

Robinson, E. J., Haigh, S. N., \& Pendle, J. E. C. (2008) Children's working understanding of the knowledge gained from seeing and feeling. Developmental Science, 11, 299-305.

Robinson, E. J., \& Nurmsoo, E. (2009) When do children learn from unreliable speakers? Cognitive Development, 24, 16-22.

Robinson, E. J., \& Whitcombe, E. (2003). Children's suggestibility in relation to their understanding about sources of knowledge. Child Development, 74(1), 48-62.

Wellman, H. M., Hollander, M., \& Shult, C. A. (1996). Young children's understanding of thought bubbles and of thoughts. Child Development, 67, 768-788.

Whitcombe, E., \& Robinson, E. J. (2000). Children's decisions about what to believe and their ability to report the source of their belief. Cognitive Development, 15, 329-346.

Received 2 I July 2009; revised version received 9 March 201 I 